\title{
Blood pressure responsiveness to obstructive events during sleep after chronic CPAP
}

\author{
O. Marrone, A. Salvaggio, M.R. Bonsignore, G. Insalaco, G. Bonsignore
}

Blood pressure responsiveness to obstructive events during sleep after chronic CPAP. O. Marrone, A. Salvaggio, M.R. Bonsignore, G. Insalaco, G. Bonsignore. (C) ERS Journals Ltd 2003.

ABSTRACT: The aim of this study was to investigate whether chronic continuous positive airway pressure (CPAP) affects blood pressure (BP) responsiveness to obstructive events occurring on the first night of CPAP withdrawal in obstructive sleep apnoea (OSA) after chronic treatment.

Thirteen male subjects with severe OSA underwent nocturnal polysomnography with beat-by-beat BP monitoring before treatment and after $4.9 \pm 3.4$ months of home CPAP (mean daily use $5.1 \pm 1.7 \mathrm{~h})$. Variations in oxyhaemoglobin saturation $\left(\Delta S_{\mathrm{a}}, \mathrm{O}_{2}\right)$, systolic $(\Delta P \mathrm{~s})$, and diastolic $(\Delta P \mathrm{~d}) \mathrm{BP}$ within nonrapid eye movement apnoeas and hypopnoeas were measured on a sample of pre- and post-treatment events. In addition, a pretreatment sample was selected for $\Delta S_{\mathrm{a}}, \mathrm{O}_{2}$ to match post-treatment events.

The higher the mean $\Delta S_{\mathrm{a}}, \mathrm{O}_{2}$ was in the full pretreatment sample, the more $\Delta S_{\mathrm{a}}, O_{2}$, $\Delta P$ s and $\Delta P \mathrm{~d}$ were attenuated after treatment. Mean $\Delta P$ s decreased from $47.3 \pm 8.5$ in the full pretreatment sample to $42.2 \pm 6.9$ in the selected pretreatment sample, to $31.5 \pm 5.9 \mathrm{mmHg}$ in the post-treatment sample. The post-treatment value differed significantly from both the pretreatment values. The corresponding values for mean $\Delta \boldsymbol{P}_{\mathrm{d}}$ were $27.0 \pm 3.5,24.0 \pm 3.1$ and $19.6 \pm 3.7 \mathrm{mmHg}$, with all values differing significantly from each other.

Chronic continuous positive airway pressure is followed by a decrease in apnoea/ hypopnoea-related blood pressure swings, possibly secondary to both reduced severity of event-related hypoxaemia and decreased responsiveness to obstructive events secondary to chronic prevention of nocturnal intermittent hypoxaemia.

Eur Respir J 2003; 21: 509-514.
Institute of Biomedicine and Molecular Immunology, Section of Respiratory Pathophysiology, National Research Council, Palermo, Italy.

Correspondence: O. Marrone, Consiglio Nazionale delle Ricerche, IBIM, Fisiopatologia Respiratoria, Via Ugo La Malfa, 153, 90146 Palermo, Italy. Fax: 39916809122

E-mail: marrone@ifr.pa.cnr.it

Keywords: Blood pressure

continuous positive airway pressure hypoxaemia

obstructive sleep apnoea

Received: May 142002

Accepted after revision: October 23 2002

This study was performed for the "Protocollo d'intesa della Ricerca Finalizzata 2000", developed with Fondazione don Carlo Gnocchi Onlus, Convenzione ICS 030.7/RF 00.80.
Continuous positive airway pressure (CPAP) is the most effective treatment for obstructive sleep apnoea (OSA). It abolishes upper airway obstruction during sleep for as long as it is applied, but its withdrawal is promptly followed by a reappearance of obstructive sleep-disordered breathing events, although with a lesser severity than before CPAP initiation [1-5]. Recent trials have demonstrated the efficacy of CPAP in improving daytime somnolence [6, 7]. However, other studies have shown that even a one-night withdrawal is followed by a sudden increase in sleepiness, as demonstrated by the multiple sleep latency test [3, 4].

The effects of CPAP on systemic blood pressure (BP) are less well understood. Despite contrasting results, most investigations demonstrate some decrease in BP after prolonged treatment [8-13]. In most studies, the effect of prolonged OSA treatment on BP was explored by comparing BP values recorded in the $24 \mathrm{~h}$ before CPAP initiation with those after treatment, by means of ambulatory intermittent BP monitoring [9-16]. CPAP was withdrawn in only one study [14] during BP monitoring performed after home treatment, while in most other studies CPAP was applied during the night $[8,9,11,12]$. Importantly, this approach may affect nocturnal results: the extent of which a nocturnal decrease in BP is due to acute rather than chronic apnoea prevention is not clear, because CPAP, applied acutely, may decrease systolic nocturnal BP values in patients with sleep respiratory disorders [17, 18]. Besides, intermittent BP sampling during the night in untreated subjects with severe OSA may lead to an important over- or underestimation of average BP [19].
In this study, nocturnal BP swings, recorded beat-by-beat in patients with OSA, in nonrapid eye movement (NREM) apnoeas and hypopnoeas before and after chronic CPAP treatment at CPAP withdrawal were compared to verify whether chronic prevention of respiratory disturbances may be followed by a variation in the responsiveness of BP to the respiratory events. In addition, this study could help clarify whether the previously reported nocturnal BP decrease during chronic CPAP treatment may be attributed just to apnoea prevention or also to the effects of prolonged regularisation of nocturnal breathing.

\section{Patients and methods}

Among subjects routinely undergoing standard polysomnography for suspected OSA, 13 consecutive patients were selected on the basis of the following characteristics: male sex, apnoea/hypopnoea index (AHI) $>30$, oxyhaemoglobin saturation $\left(\mathrm{Sa}, \mathrm{O}_{2}\right)$ while awake $>90 \%$, and no pharmacological treatment, diabetes or clinical evidence of cardiac disease. Diurnal BP was measured in the morning in the sitting position after a $15-\mathrm{min}$ resting period. It was normal $(\leqslant 140$ over $90 \mathrm{mmHg})$ in 10 subjects and mildly elevated $(\leqslant 150$ over $95 \mathrm{mmHg}$ ) in the remaining three.

All subjects were prescribed CPAP for home treatment after manual nocturnal titration. After $4.9 \pm 3.4$ months the patients were re-evaluated. Total hours of CPAP usage were checked by means of a ventilator in-built time counter, and mean daily 
Table 1.-Characteristics of the patients before and after continuous positive airway pressure treatment

Before treatment After treatment p-value

\begin{tabular}{lccc}
\hline Age yrs & $47.7 \pm 8.7$ & & \\
Weight $\mathrm{kg}$ & $95.8 \pm 13.5$ & $92.7 \pm 14.7$ & $*$ \\
$\mathrm{BMI} \mathrm{kg} \cdot \mathrm{m}^{-2}$ & $33.7 \pm 3.9$ & $32.6 \pm 4.0$ & $*$ \\
Morning $P$ s $\mathrm{mmHg}$ & $128.5 \pm 13.9$ & $130.4 \pm 13.9$ & NS \\
Morning $P$ d mmHg & $83.5 \pm 7.7$ & $82.7 \pm 8.3$ & NS \\
\hline
\end{tabular}

Data are presented as mean \pm SD. BMI: body mass index; $P_{\mathrm{s}}$ : systolic blood pressure; $P$ d: diastolic blood pressure; NS: nonsignificant. $*$ : $\mathrm{p}<0.05$

CPAP use was calculated as total hours divided by number of days with CPAP at home. Body weight and diurnal BP were controlled. After ensuring that CPAP had been used the night before, a polysomnographic study was repeated without CPAP application, i.e. on the first night of CPAP withdrawal.

Polysomnograhic studies included electroenchelography (EEG; unipolar leads C3A2 and O1A2), right and left electrooculography, submental electromyography, thoracic and abdominal movements, oronasal airflow, $\mathrm{Sa}_{1} \mathrm{O}_{2}$ (Biox 3740 ear oximeter; Ohmeda, Louisville, CO, USA), body posture, and BP (Finapres 2300; Ohmeda). Finapres was automatically turned off for $5 \mathrm{~min}$ every $40 \mathrm{~min}$ to avoid finger discomfort. Apnoeas were scored when airflow was absent for $\geqslant 10 \mathrm{~s}$, and were classified as central, mixed or obstructive according to standard criteria. Hypopnoeas were considered to be discernible reductions in airflow associated with either arousal or an $\mathrm{Sa}_{\mathrm{a}} \mathrm{O}_{2}$ fall of $\geqslant 4 \%$. AHI was calculated as (number of apnoeas+number of hypopnoeas)/hour of sleep time.

$\mathrm{BP}$ and $\mathrm{Sa}, \mathrm{O}_{2}$ behaviour were evaluated on apnoeas and hypopnoeas in NREM sleep before and after treatment. In each patient, both before and after treatment, all apnoeic and hypopnoeic events with a BP signal free from artefacts over the whole respiratory event, and the following unoccluded ventilatory interval were considered for BP measurements. Events during which the Finapres device operated servo set-point adjustments that could affect the evaluation of BP swings were excluded; events had to be separated from an REM period by $\geqslant 10 \mathrm{~min}$, as sleep stage may influence BP behaviour during sleep in OSA [20]. The following variables were measured: difference between highest BP after and lowest BP during the event (systolic $(\Delta P \mathrm{~s})$ and diastolic $(\Delta P \mathrm{~d}) \mathrm{BP}$ values, respectively), highest $\mathrm{Sa}, \mathrm{O}_{2}$ preceding the event, lowest $\mathrm{Sa}, \mathrm{O}_{2}$ following the event, and difference between these two values $\left(\Delta S \mathrm{a}, \mathrm{O}_{2}\right)$. The lowest $P_{\mathrm{s}}$ and $P \mathrm{~d}$ values were taken during expiratory time, in order to exclude acutely decreasing BP values caused by negative intrathoracic pressure. Absolute BP values were not considered in the analysis since the Finapres device is more accurate in detecting BP changes than its absolute levels [21]. Finally, out of the pretreatment apnoeas and hypopnoeas, a subsample of events was selected to match events with similar degrees of oxygen desaturation before and after treatment. The selection was operated by progressively eliminating the most desaturating events, until the remaining ones showed a mean $\Delta S \mathrm{~S}, \mathrm{O}_{2}$ that differed from the $\Delta S \mathrm{a}, \mathrm{O}_{2}$ of the post-treatment events $< \pm 1 \%$.

Anthropometric and polysomnographic data before and after treatment were compared by means of two-tailed Student's t-test for paired data. The events chosen for analysis in each subject were identified as full pretreatment, selected pretreatment and post-treatment samples, respectively. Differences in BP and $\mathrm{Sa}, \mathrm{O}_{2}$ behaviour among respiratory events of the three samples were evaluated by one-way analysis of variance for repeated measures, followed by Scheffé's test for paired comparisons. Correlations between variables were
Table 2.-Polysomnographic data before and after continuous positive airway pressure treatment

Before treatment After treatment p-value

\begin{tabular}{lccc}
\hline TST min & $268.7 \pm 56.0$ & $248.7 \pm 70.4$ & NS \\
Subjects with REM & 12 & 7 & \\
REM \%TST & $9.8 \pm 4.8$ & $6.2 \pm 3.9$ & NS \\
Arousal index & $74.3 \pm 18.8$ & $61.7 \pm 20.6$ & NS \\
AHI & $80.1 \pm 13.4$ & $64.6 \pm 24.6$ & $*$ \\
AHI NREM & $81.3 \pm 15.8$ & $64.7 \pm 24.5$ & $*$ \\
AHI REM & $66.2 \pm 13.5$ & $65.3 \pm 30.3$ & NS \\
AI NREM & $74.0 \pm 18.8$ & $53.3 \pm 28.0$ & $\#$ \\
HI NREM & $7.3 \pm 8.3$ & $11.4 \pm 28.6$ & NS \\
AH in NREM & $27.4 \pm 6.8$ & $25.2 \pm 9.2$ & NS
\end{tabular}

Data are presented as mean \pm SD. TST: total sleep time; REM: rapid eye movement; AHI: apnoea/hypopnoea index; NREM: nonrapid eye movement; AI: apnoea index; HI: hypopnoea index; $\mathrm{AH}$ : apnoea and hypopnoea duration; NS: nonsignificant. *: $\mathrm{p}<0.05 ;{ }^{\#}: \mathrm{p}<0.005$.

assessed by linear regression analysis. A p-value of $<0.05$ was considered significant.

\section{Results}

Characteristics of the patients are shown in table 1 . No significant changes in diurnal BP were observed after treatment. On average, patients showed a good compliance to CPAP treatment (mean daily use $5.1 \pm 1.7 \mathrm{~h}$ ).

Data obtained from polysomnographic studies are shown in table 2. After treatment, patients showed a lower AHI, either if calculated on total sleep time or on NREM sleep alone. The decrease in AHI was accounted for by a decrease in apnoeas, since the rate of hypopneas remained unmodified. Mean NREM apnoea/hypopnea duration did not change significantly.

Data measured in the samples of events analysed in both studies are shown in table 3 . The number of respiratory events analysed in each patient in the full pretreatment sample and in the post-treatment sample represented $30.9 \pm 4.3 \%$ and $29.1 \pm 7.1 \%$ of the total number of respiratory events in NREM sleep,

Table 3.-Blood pressure and oxyhaemoglobin saturation in the analysed events

\begin{tabular}{|c|c|c|c|}
\hline & \multicolumn{2}{|c|}{ Before treatment } & \multirow{2}{*}{$\begin{array}{l}\text { After } \\
\text { treatment }\end{array}$} \\
\hline & Full sample & Selected sample & \\
\hline Events analysed $n$ & $104 \pm 29$ & $45 \pm 29$ & $73 \pm 38$ \\
\hline$\Delta P_{\mathrm{s}} \mathrm{mmHg}$ & $47.3 \pm 8.5$ & $42.2 \pm 6.9$ & $31.5 \pm 5.9^{\#, \oplus}$ \\
\hline$\Delta P \mathrm{~d} \mathrm{mmHg}$ & $27.0 \pm 3.5$ & $24.0 \pm 3.1 *$ & $19.6 \pm 3.7^{\#, \oplus}$ \\
\hline$\Delta S \mathrm{a}, \mathrm{O}_{2} \%$ & $10.5 \pm 3.4$ & $6.9 \pm 2.7 *$ & $6.7 \pm 2.7^{\bullet}$ \\
\hline $\begin{array}{l}\text { Mean } S \mathrm{a}, \mathrm{O}_{2} \\
\quad \text { before events \% }\end{array}$ & $95.1 \pm 2.0$ & $95.0 \pm 2.1$ & $96.0 \pm 1.3$ \\
\hline $\begin{array}{c}\text { Mean lowest } \mathrm{Sa}_{\mathrm{a}} \mathrm{O}_{2} \\
\text { after events } \%\end{array}$ & $84.6 \pm 4.2$ & $88.2 \pm 3.4^{\#}$ & $89.3 \pm 2.5^{\bullet}$ \\
\hline
\end{tabular}

Data are presented as mean $\pm \mathrm{SD} . \Delta P_{\mathrm{s}}$ : difference between highest systolic blood pressure value after, and lowest value during, apnoeic/hypopnoeic events; $\Delta P \mathrm{~d}$ : difference between highest diastolic blood pressure value after, and lowest value during, apnoeic/hypopnoeic events; $\Delta S_{\mathrm{a}}, \mathrm{O}_{2}$ : difference between highest oxyhaemoglobin saturation value preceding and lowest oxyhaemoglobin saturation value following apnoeic/hypopnoeic events. *: $\mathrm{p}<0.05$ versus full pretreatment sample; ${ }^{\#}$ : $\mathrm{p}<0.005$ versus full pretreatment sample; ${ }^{\uparrow}: \mathrm{p}<0.05$ versus selected pretreatment sample. 
respectively. From the full pretreatment to the post-treatment sample, $\Delta P \mathrm{~s}, \Delta P \mathrm{~d}$ and $\Delta S \mathrm{a}, \mathrm{O}_{2}$ changed by a variable extent among subjects. On average, $\Delta P \mathrm{~s}$ and $\Delta P \mathrm{~d}$ decreased by $15.8 \mathrm{mmHg}$ (range $-0.1--41.4$ ) and $7.5 \mathrm{mmHg}$ (range $-0.4-16.9)$, respectively. Neither the decrease in $\Delta P$ s nor in $\Delta P$ d were correlated to age, body mass index (BMI) or AHI values either before or after treatment, to a decrease in BMI or $\mathrm{AHI}$, or to CPAP use. Both the decrease in $\Delta P$ s and $\Delta P \mathrm{~d}$ were correlated to the $\Delta S \mathrm{a}, \mathrm{O}_{2}$ value before treatment $(\mathrm{r}=0.77$ and 0.73 , respectively, $\mathrm{p}<0.005$; fig. 1 ). On average, $\Delta \mathrm{Sa}_{2} \mathrm{O}_{2}$ decreased by $3.4 \%$ (range $0.9-9.5 \%$ ). The change in $\Delta \mathrm{Sa}, \mathrm{O}_{2}$ was due to a significant increase in mean lowest $\mathrm{Sa}, \mathrm{O}_{2}$ following respiratory events (from $84.6 \pm 4.2 \%$ to $89.3 \pm 2.5 \%, \mathrm{p}<0.001$ ) associated with a nonsignificant change in mean $\mathrm{Sa}_{2} \mathrm{O}_{2}$ preceding them (from $95.1 \pm 2.0 \%$ to $96.0 \pm 1.3 \%$ ). In the group of patients, the larger the $\Delta S \mathrm{a}, \mathrm{O}_{2}$ before treatment, the larger the decrease after treatment $(\mathrm{r}=0.63, \mathrm{p}<0.025)$.

Among the pretreatment events, $45 \pm 29$ events per patient were further selected to match $\mathrm{Sa}_{2} \mathrm{O}_{2}$ features of the posttreatment sample. Mean $\Delta P \mathrm{~s}, \Delta P \mathrm{~d}$ and $\Delta S \mathrm{a}, \mathrm{O}_{2}$ values measured in all subjects in the respiratory events of the full pretreatment, selected pretreatment, and post-treatment sample are shown in table 3, while mean individual data are shown in figure 2. Mean $\Delta P$ s did not differ significantly between full versus selected
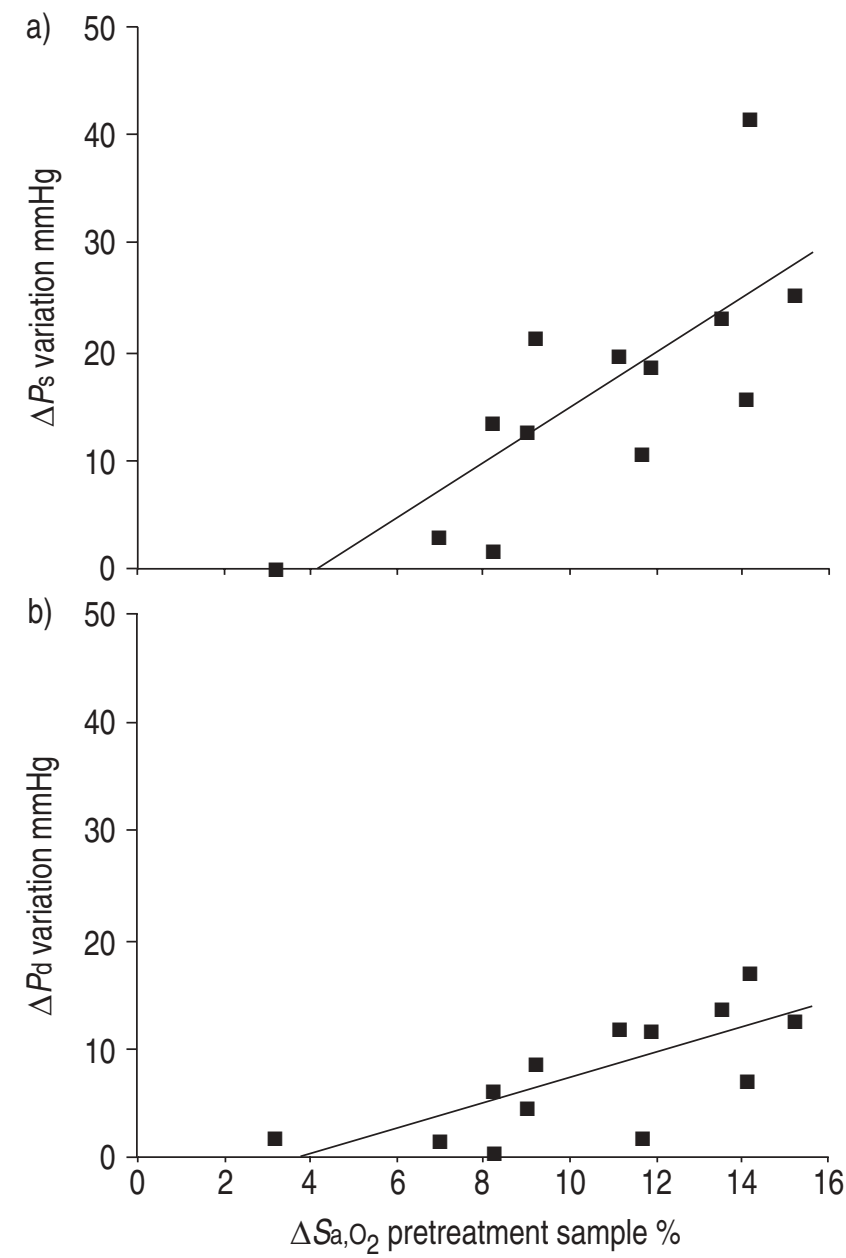

Fig. 1. - Correlation between mean oxyhaemoglobin saturation swings $\left(\Delta S \mathrm{a}_{1} \mathrm{O}_{2}\right)$ recorded in each patient in apnoeic and hypopnoeic events included in the full pretreatment sample, and the difference in a) mean systolic $\left(\Delta P_{\mathrm{s}}\right)$ or $\left.\mathrm{b}\right)$ diastolic $\left(\Delta P_{\mathrm{d}}\right)$ blood pressure swings between respiratory events included in the full pretreatment sample and those included in the post-treatment sample.
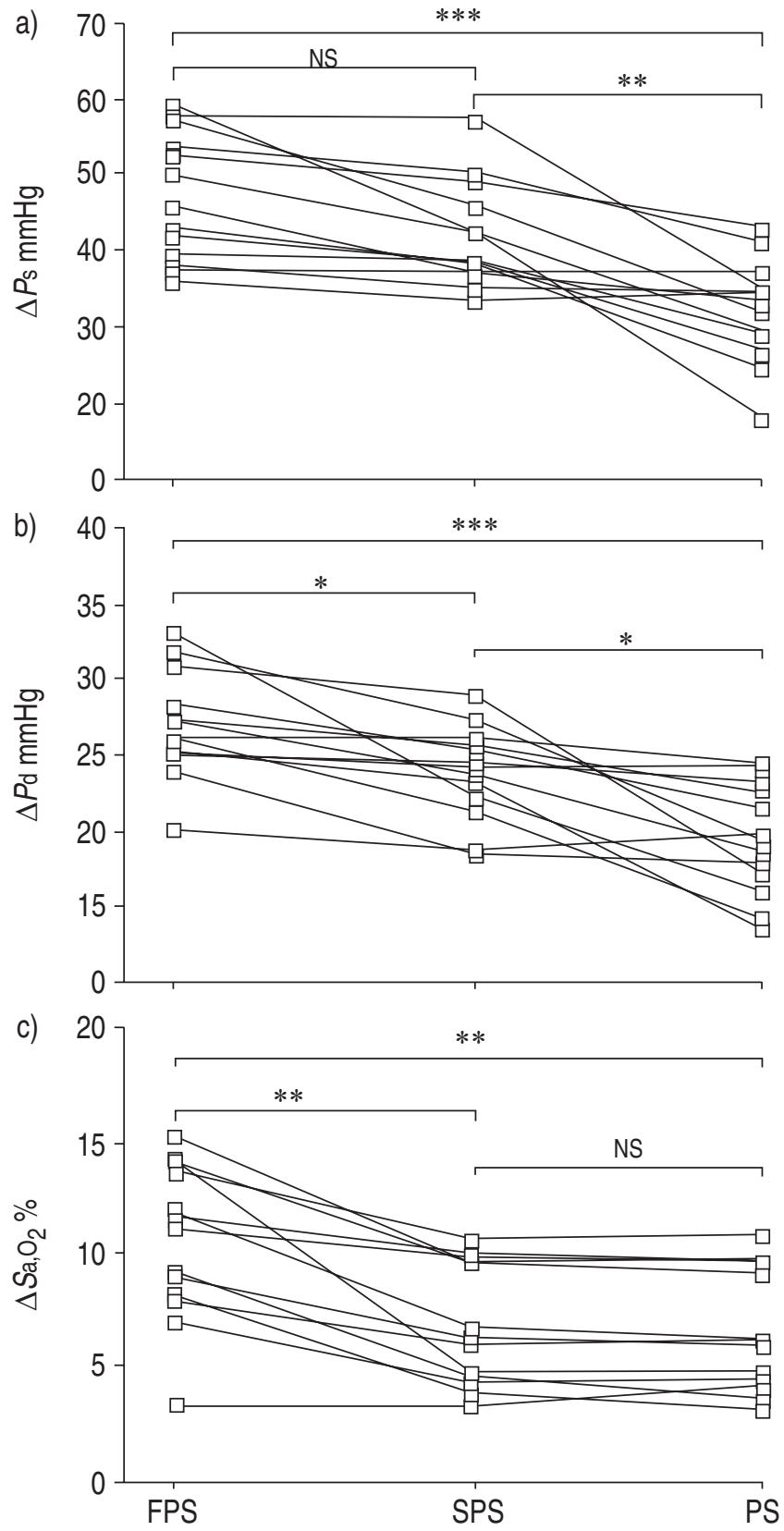

Fig. 2. - Mean values of a) systolic blood pressure swing $\left(\Delta P_{\mathrm{s}}\right)$, b) diastolic blood pressure swing $(\Delta P \mathrm{~d})$, and c) oxyhaemoglobin saturation swing $\left(\Delta \mathrm{Sa}_{\mathrm{a}, \mathrm{O}_{2}}\right)$, recorded in each patient in the full pretreatment (FPS), selected pretreatment (SPS) and post-treatment (PS) apnoea and hypopnoea samples. NS: nonsignificant. ${ }^{*}: \mathrm{p}<0.05 ; * *: \mathrm{p}<0.01 ; * * *: \mathrm{p}<0.001$.

pretreatment samples, while both values were significantly higher than the value in the post-treatment sample. Mean $\Delta P \mathrm{~d}$ showed a progressive significant decrease from the full pretreatment sample to the selected pretreatment sample to the post-treatment sample. Mean $\Delta \mathrm{Sa}_{2} \mathrm{O}_{2}$ was significantly higher in the full pretreatment sample than in both the selected pretreatment and post-treatment samples.

\section{Discussion}

Acute CPAP withdrawal after chronic treatment was followed by reductions in the amplitude of apnoea/hypopnoea-related BP swings. These reductions were strongly related to the amplitude 
of $\mathrm{Sa}, \mathrm{O}_{2}$ falls occurring with obstructive events before CPAP treatment.

In addition to the reduction in BP swings, the severity of sleep respiratory disorders decreased after CPAP. This finding is in agreement with several previous reports of changes in characteristics of breathing during sleep at CPAP withdrawal, consisting of a decrease in AHI [2-4], in $S \mathrm{a}, \mathrm{O}_{2}$ falls [2, 4, 5], or decrease in apnoeas unaccompanied by a decrease in hypopnoeas [22]. In this study, the combination of a small increase in the percentage of hypopnoeas over the total number of respiratory disorders, a minor decrease in event duration and a minor increase in $\mathrm{Sa}, \mathrm{O}_{2}$ preceding the events may have led to the attenuation in $\mathrm{Sa}, \mathrm{O}_{2}$ falls induced by the sleep respiratory disorders. As demonstrated previously [1], the reduction in $\mathrm{Sa}, \mathrm{O}_{2}$ falls was more evident in the subjects with the most severe desaturations before treatment. The causes of the improvement in breathing after CPAP have not been clarified; a decrease in upper airway oedema, an improvement in genioglossal function or an increase in responsiveness to chemical stimuli have been suggested as possible explanations.

BP behaviour in obstructive events during sleep is influenced by several different tightly intercorrelated factors, including event duration, oesophageal pressure, arousals, chemical stimuli, and autonomic nervous system activity. The duration of events, which has been reported as one of the most important correlates of postapnoeic BP rise [23], remained almost unmodified and probably did not significantly affect the changes in BP behaviour.

Oesophageal pressure was not measured. One study showed that oesophageal pressure swings at CPAP withdrawal after chronic CPAP decreases [5]. If a similar decrease occurred in the subjects in this study, it could have affected BP during apnoeas. However, negative intrathoracic pressure during apnoeas transiently reduces BP during each respiratory effort, but exerts no major effect on BP after the effort release [24]. BP measurements during apnoeas were always taken during the expiratory portion of the occluded breath so that the most prominent possible effect of strong respiratory efforts could not influence the calculated BP swing.

Arousals occurred at the end of most events both before and after treatment. Almost all arousals occurred at the end of respiratory events. BP rise after sleep-disordered breathing events is influenced by arousal duration [25] and it could also be affected by its EEG expression [26]. More studies are warranted to investigate whether CPAP treatment is followed by changes in the characteristics of arousals that could affect BP behaviour.

Some effects of chronic CPAP could also result from relief of sleepiness. Recovery from sleep deprivation could reduce BP reactivity, as demonstrated in dogs in which sleep deprivation increases BP response to airway obstruction. However, as apnoea-induced hypoxaemia worsened after sleep deprivation, it is possible that the effect on BP was mediated by the increase in hypoxaemia [27].

Hypoxaemia and BP in OSA are strongly related. In each apnoea, BP rise and $\mathrm{Sa}, \mathrm{O}_{2}$ falls are significantly correlated [28-30]. Although BP after apnoeas may rise even when hypoxaemia is heavily blunted by oxygen administration [23, $31,32]$, hypoxaemia is recognised as one of the most important factors contributing to the BP rise [33]. As discussed below, the results of this study lend further support to an influence of hypoxaemia on BP behaviour.

The authors observed that larger $\mathrm{Sa}_{\mathrm{a}} \mathrm{O}_{2}$ swings before treatment gave rise to more attenuated BP swings by CPAP treatment, suggesting that chronic prevention of large $\mathrm{Sa}, \mathrm{O}_{2}$ swings led to a decrease in $\mathrm{BP}$ responsiveness to obstructive events and, as a consequence, to an attenuation of BP oscillations. However, $\Delta \mathrm{Sa}, \mathrm{O}_{2}$ after treatment was attenuated proportionally to the amplitude of $\mathrm{Sa}, \mathrm{O}_{2}$ swings before treatment, as a result of an increase in postapnoeic $\mathrm{Sa}, \mathrm{O}_{2}$. Contrary to the previous hypothesis, this could suggest that BP swings decreased because characteristics of the events that reappeared after treatment resembled those of the least severe events recorded before treatment. In other words, treatment might have not modified the BP responsiveness to obstructive events, but BP showed smaller oscillations, as hypertensive stimuli, including hypoxaemia, were weaker. The detection of smaller BP swings in the events selected for mild desaturations before treatment (selected pretreatment samples) compared with the events recorded during the same night that showed larger mean $\mathrm{Sa}, \mathrm{O}_{2}$ falls (full pretreatment samples), supports the fact that the lesser severity of hypoxaemia, such as that found after treatment, could contribute to the decrease in BP swings.

However, the prevention of chronic intermittent hypoxaemia with CPAP may also attenuate BP reactivity to apnoeas and hypopnoeas. Indeed, this study found lower BP swings in the post-treatment events (post-treatment samples) compared with the pretreatment events with similar oxygen desaturations (selected pretreatment samples), in agreement with a chronic effect of hypoxaemia on increasing BP reactivity to apnoeas. In animals, chronic intermittent hypoxaemia enhances the acute BP response to hypoxia through increased sympathetic activity [34], which, in turn, influences postapnoeic BP rise [35-37]. Similarly, in normal male humans, exposure to hypoxia for 1 month, in a high-altitude environment increased BP responsiveness to hypoxia. This increase was associated with a parallel increase in BP oscillations during periodic breathing in NREM sleep [38]. Sympathetic tone has been observed to decrease after prolonged OSA treatment [14, 39-41], whereas baroreflex control of heart rate improves $[42,43]$. The authors hypothesise that the improvement in autonomic control is more prominent in subjects with large oxygen desaturations, and that this may contribute to the observed reduction in BP responsiveness to apnoeas. In fact, no decrease in BP swings occurred in the patients with mild degrees of hypoxaemia during sleep before treatment.

It could be suggested that some of the responsiveness to BP of the events of the pretreatment selected samples was due to a carry-over effect of hypoxaemia produced by the surrounding apnoeas. However, although exposure to hypoxia causes an increase in sympathetic discharge that outlasts its duration by some minutes, reversal of hypoxia is followed readily by a return to baseline of both heart rate and BP [44, 45].

In summary, the data of this study, although not excluding possible roles of many different pathogenetic factors, suggest that blunting of apnoea/hypopnoea-related hypoxaemia and prevention of chronic intermittent hypoxaemia are among the most important factors responsible for the attenuation of BP swings during obstructive events after chronic CPAP treatment.

No other study has examined changes in nocturnal BP behaviour at CPAP withdrawal. As in previous investigations that evaluated breathing during sleep at CPAP withdrawal, the first night after CPAP was taken into account in this study. Since prolonged interruption of CPAP may be followed by a progressive worsening, towards the pretreatment condition, of sleep respiratory disorders and of their consequences, it was necessary to analyse data collected during the first night of CPAP withdrawal. Such analysis may provide the best possible data to demonstrate a possible carry-over effect of CPAP on BP responsiveness to obstructive apnoeas and hypopnoeas.

Recent controlled studies were able to demonstrate a role for chronic CPAP treatment in decreasing daytime BP with relatively large samples of patients. The absolute decrease in $\mathrm{BP}$, although statistically significant, was quite small [12, 13]. Although no significant change in morning BP was found in this study after CPAP, the patient sample may have been insufficient to show significant changes in values measured only during one morning visit. Most studies on BP before and after 
CPAP in OSA were performed by ambulatory BP monitoring [9-16]. Although such instruments are accurate for diurnal measurements of absolute BP values in isolated heart beats, they have limitations in that they cannot detect the very rapid BP changes occurring in apnoea-ventilation cycles in OSA. Furthermore, the high short-term variability of nocturnal BP in OSA lessens the accuracy of the assessment of mean nocturnal BP values at usual rates of BP sampling [19]. For the nocturnal measurements, a device (Finapres) that is able to monitor beat-by-beat BP noninvasively was used, which is invaluable for the detection of the fast BP changes occurring in apnoea-ventilation cycles. Measurements performed by Finapres proved accurate with regard to BP variations, but may be rather inaccurate for absolute $\mathrm{BP}$ values [21]. BP measurements by Finapres are critically dependent on the position of the hand where the probe is applied, as any change in hand position causes a shift in BP readings. While artefactual changes in BP readings related to hand movements are easy to detect in single apnoea-ventilation cycles, they are difficult to identify when comparing different parts of one nocturnal recording. Therefore, the analysis was limited to BP swings and did not take into consideration absolute BP values. The search for events in which all BP signal requirements were fulfilled and separated from REM sleep by $>10 \mathrm{~min}$ led to the selection of approximately one-third of the respiratory events for BP analysis. Nevertheless, the number of events analysed was a substantial percentage $(30 \%)$ of the total respiratory events. It has been demonstrated that analysing $\leqslant 25 \%$ of a polysomnographic study in patients with OSA provides a fully reliable assessment of most sleep and respiratory parameters [46].

The data obtained may have interesting implications for the interpretation of the data from previous studies in which the effects of chronic CPAP on BP were explored. Although a similar decrease in diurnal and nocturnal BP after CPAP, as found in some studies [9, 13], can be attributed to effects of chronic treatment, it is not clear if a reduction in BP limited to [15] or prevalent in $[8,12]$ the nocturnal hours during CPAP application, may be the acute consequence of apnoea prevention or a chronic effect of regularisation of breathing. These results suggest that in subjects who had mild desaturations before treatment, a purely nocturnal decrease in BP could be mainly an acute effect of apnoea prevention by CPAP administration, while in subjects with severe desaturations, it could also be a consequence of the chronic treatment. In future studies, it would be interesting to separately analyse the effects of long-term CPAP on absolute 24-h BP values in subjects with different degrees of apnoea-induced hypoxaemia.

In conclusion, continuous positive airway pressure withdrawal after chronic treatment is associated with a decrease in apnoea/ hypopnoea-related blood pressure swings that are proportional to the degree of hypoxaemia induced by the obstructive events before treatment initiation. This decrease could be secondary to both the acute effect of a reduction in apnoea-induced hypoxaemia at continuous positive airway pressure withdrawal and to a decrease in blood pressure responsiveness to obstructive events due to chronic prevention of nocturnal intermittent hypoxaemia. These results suggest that the detection of a decrease in nocturnal blood pressure during continuous positive airway pressure administration after chronic continuous positive airway pressure treatment may be secondary to the simple effect of apnoea prevention when apnoeas provoke mild nocturnal hypoxaemia, and also to an effect of chronic treatment when they induce severe hypoxaemia.

\section{References}

1. Collop NA, Block AJ, Hellard D. The effect of nightly nasal CPAP treatment on underlying obstructive sleep apnea and pharyngeal size. Chest 1991; 99: 855-860.
2. Leech JA, Onal E, Lopata M. Nasal CPAP continues to improve sleep-disordered breathing and daytime oxygenation over long-term follow-up of occlusive sleep apnea syndrome. Chest 1992; 102: 1651-1655.

3. Kribbs NB, Pack AI, Kline LR, et al. Effects of one night without nasal CPAP treatment on sleep and sleepiness in patients with obstructive sleep apnea. Am Rev Respir Dis 1993; 147: 1162-1168.

4. Sforza E, Lugaresi E. Daytime sleepiness and nasal continuous positive airway pressure therapy in obstructive sleep apnea syndrome patients: effects of chronic treatment and 1-night therapy withdrawal. Sleep 1995; 18: 195-201.

5. Boudewyns A, Sforza E, Zamagni M, Krieger J. Respiratory effort during sleep apneas after interruption of long-term CPAP treatment in patients with obstructive sleep apnea. Chest 1996; 110: 120-127.

6. Jenkinson C, Davies RJO, Mullins R, Stradling JR. Comparison of therapeutic and subtherapeutic nasal continuous positive airway pressure for obstructive sleep apnoea: a randomised trial. Lancet 1999; 353: 2100-2105.

7. Ballester E, Badia JR, Hernàndez L, et al. Evidence of the effectiveness of continuous positive airway pressure in the treatment of sleep apnea/hypopnea syndrome. Am J Respir Crit Care Med 1999; 159: 495-501.

8. Mayer J, Becker H, Brandenburg U, Penzel T, Peter JH, von Wichert P. Blood pressure and sleep apnea: results of longterm nasal continuous positive airway pressure therapy. Cardiology 1991; 79: 84-92.

9. Suzuki M, Otsuka K, Guilleminault C. Long-term nasal continuous positive airway pressure administration can normalize hypertension in obstructive sleep apnea patients. Sleep 1993; 16: 545-549.

10. Wilcox I, Grunstein RR, Hedner JA, et al. Effect of nasal continuous positive airway pressure during sleep on 24-hour blood pressure in obstructive sleep apnea. Sleep 1993; 16: 539-544.

11. Voogel AJ, van Steenwijk RP, Karemaker JM, van Montfrans GA. Effects of treatment of obstructive sleep apnea on circadian hemodynamics. J Auton Nerv Syst 1999; 77: $177-183$

12. Faccenda JF, Mackay TW, Boon NA, Douglas NJ Randomized placebo-controlled trial of continuous positive airway pressure on blood pressure in the sleep apneahypopnea syndrome. Am J Respir Crit Care Med 2001; 163 344-348.

13. Pepperell JCT, Ramdassingh-Dow S, Crosthwaite $\mathrm{N}$, et al. Ambulatory blood pressure after therapeutic and subtherapeutic nasal continuous positive airway pressure for obstructive sleep apnoea: a randomised parallel trial. Lancet 2002; 359: 204-210.

14. Hedner J, Darpö B, Ejnell H, Carlson J, Caidahl K. Reduction in sympathetic activity after long-term CPAP treatment in sleep apnoea: cardiovascular implications. Eur Respir J 1995; 8: 222-229.

15. Davies RJI, Crosby J, Prothero A, Stradling JR. Ambulatory blood pressure and left ventricular hypertrophy in subjects with untreated obstructive sleep apnoea and snoring, compared with matched control subjects, and their response to treatment. Clin Sci 1994; 86: 417-424.

16. Barbé F, Mayoralas LR, Duran J, et al. Treatment with continuous positive airway pressure is not effective in patients with sleep apnea but no daytime sleepiness. A randomized, controlled trial. Ann Intern Med 2001; 134: $1015-1023$.

17. Sforza E, Capechi V, Lugaresi E. Haemodynamic effects of short-term nasal continuous positive airway pressure therapy in sleep apnoea syndrome: monitoring by a finger arterial pressure device. Eur Respir J 1992; 5: 858-863.

18. Tkacova R, Rankin F, Fitzgerald FS, Floras JS, Bradley TD. Effects of continuous positive airway pressure on obstructive sleep apnea and left ventricular afterload in patients with heart failure. Circulation 1998; 98: 2269-2275. 
19. Marrone O, Romano S, Insalaco G, Bonsignore MR, Salvaggio A, Bonsignore G. Influence of sampling interval on the evaluation of nocturnal blood pressure in subjects with and without obstructive sleep apnoea. Eur Respir $J$ 2000; 16: 653-658.

20. Garpestad E, Ringler J, Parker A, Remsburg S, Weiss JW. Sleep stage influences the hemodynamic response to obstructive sleep apneas. Am J Respir Crit Care Med 1995; 152: 192203.

21. Imholz BPM, Wieling W, van Montfrans GA, Wesseling KH. Fifteen years experience with finger arterial pressure monitoring: assessment of the technology. Cardiovasc Res 1998; 38: 605-616.

22. McEvoy RD, Thornton AT. Treatment of obstructive sleep apnea syndrome with nasal continuous positive airway pressure. Sleep 1984; 7: 313-325.

23. Ali NJ, Davies RJO, Fleetham JA, Stradling JR. The acute effects of continuous positive airway pressure and oxygen administration on blood pressure during obstructive sleep apnea. Chest 1992; 101: 1526-1532.

24. Morgan PJ, Denahan T, Ebert TJ. Neurocirculatory consequences of negative intrathoracic pressure vs. asphyxia during voluntary apnea. J Appl Physiol 1993; 74: 2969-2975.

25. Lofaso F, Goldenberg F, d'Ortho MP, Coste A, Harf A. Arterial blood pressure response to transient arousals from NREM sleep in nonapneic snorers with sleep fragmentation. Chest 1998; 113: 985-991.

26. Davies RJO, Bennet LS, Barbour C, Tarassenko L, Stradling JR. Second by second patterns in cortical electroencephalograph and systolic blood pressure during Cheyne-Stokes. Eur Respir J 1999; 14: 940-945.

27. O'Donnell CP, King ED, Schwartz AR, Robotham JL, Smith PL. Relationship between blood pressure and airway obstruction during sleep in the dog. J Appl Physiol 1994; 77: 1819-1828.

28. Shepard JW. Gas exchange and hemodynamics during sleep. Med Clin North Am 1985; 69: 1243-1264.

29. Okabe S, Hida W, Kikuchi Y, et al. Role of hypoxia on increased blood pressure in patients with obstructive sleep apnoea. Thorax 1995; 50: 28-34.

30. Calverley PMA, Rees K. Systemic arterial blood pressure during obstructive sleep apnoea. J Sleep Res 1995; 4: 93-96.

31. Ringler J, Basner RC, Shannon R, et al. Hypoxaemia alone does not explain blood pressure elevations after obstructive apneas. J Appl Physiol 1990; 69: 2143-2148.

32. Garpestad E, Parker JA, Katayama H, et al. Decrease in ventricular stroke volume at apnea termination is independent of oxygen desaturation. J Appl Physiol 1994; 77: 16021608 .
33. Morgan PJ, Dempsey JA, Pegelow DF, et al. Blood pressure perturbations caused by subclinical sleep-disordered breathing. Sleep 1998; 21: 737-746.

34. Bao G, Randhawa PM, Fletcher EC. Acute blood pressure elevation during repetitive hypocapnic and eucapnic hypoxia in rats. J Appl Physiol 1997; 82: 1071-1078.

35. Schneider H, Schaub CS, Chen CA, et al. Neural and local effects of hypoxia on cardiovascular responses to obstructive apnea. J Appl Physiol 2000; 88: 1093-1102.

36. Katragadda S, Xie A, Puleo D, Skatrud JB, Morgan BJ. Neural mechanisms of the pressor response to obstructive and nonobstructive apnea. J Appl Physiol 1997; 83: 20482054.

37. Leuenberger UA, Hardy JC, Herr MD, Gray K, Siniway LI. Hypoxia augments apnea-induced peripheral vasoconstriction in humans. J Appl Physiol 2001; 90: 1516-1522.

38. Insalaco G, Romano S, Salvaggio A, et al. Blood pressure and heart rate during periodic breathing while asleep at altitude. J Appl Physiol 2000; 89: 947-955.

39. Waravdekar NV, Sinoway LI, Zwillich CW, Leuenberger UA. Influence of treatment on muscle sympathetic nerve activity in sleep apnea. Am J Respir Crit Care Med 1996; 153: 1333-1338.

40. Narkiewicz K, Kato M, Phillips BA, Pesek CA, Davison DE, Somers VK. Nocturnal continuous positive airway pressure decreases daytime sympathetic traffic in obstructive sleep apnea. Circulation 1999; 100: 2332-2335.

41. Roche F, Court-Fortune I, Pichot V, et al. Reduced cardiac sympathetic autonomic tone after long-term nasal continuous positive airway pressure in obstructive sleep apnea syndrome. Clin Physiol 1999; 19: 127-134.

42. Klawe JJ, Tafil-Klawe MM, Grote L, Peter JH, Smietanowski M, Gielecki J. Carotid cardiac baroreflex improvement in obstructive sleep apnea patients following cPAP-treatment. Med Sci Monit 1999; 5: 666-668.

43. Bonsignore MR, Parati G, Insalaco G, et al. Spontaneous baroreflex control of heart rate during sleep in the obstructive sleep apnea syndrome (OSAS) before and after CPAP treatment. Am J Respir Crit Care Med 2002; 166: 279286.

44. Xie A, Skatrud JB, Crabtree DC, Puleo DS, Goodman BM, Morgan BJ. Neurocirculatory consequences of intermittent asphyxia in humans. J Appl Physiol 2000; 89: 1333-1339.

45. Xie A, Skatrud JB, Puleo DS, Morgan BJ. Exposure to hypoxia produces long-lasting sympathetic activation in humans. J Appl Physiol 2001; 91: 1555-1562.

46. Steyer BJ, Quan SF, Morgan WJ. Polysomnography scoring for sleep apnea. Use of a sampling method. Am Rev Respir Dis 1985; 131: 592-595. 